\title{
LINGUAGEM COMO ALTERNATIVA AO ASPECTO QUANTITATIVO EM PSICANÁLISE
}

\author{
Waldir Beividas \\ Universidade de São Paulo, São Paulo, Brasil \\ Tiago Ravanello* \\ Universidade Federal de Mato Grosso do Sul, Campo Grande, Brasil
}

\begin{abstract}
RESUMO: O presente artigo faz parte de uma pesquisa mais ampla que visa explorar as conseqüências intrínsecas à hipótese do inconsciente estruturado como linguagem se levada à sua radicalidade. Para tanto, focamos a problemática que envolve os conceitos referentes à energética freudiana, especialmente o de afeto, e os eventuais riscos de apropriações por projetos de agregação da psicanálise às neurociências. Ou seja, ao invés de adentrarmos nos meandros do regime quantitativo presente desde a obra freudiana e decorrentes aproximações com temas neurocientíficos, buscamos percorrer a outra possibilidade de abordagem dos fenômenos clínicos e psicopatológicos igualmente latentes no método psicanalítico, a saber, a exploração da linguagem e do sentido.
\end{abstract}

PALAVRAS-CHAVE: Psicanálise; Linguagem; Afeto.

\section{LANGUAGE AS ALTERNATIVE FOR THE QUANTITATIVE ASPECTS IN PSYCHOANALYSIS}

\begin{abstract}
The following article is included in a larger range research program that intents to explore the inner consequences of the hypothesis of the unconscious structured as a language if taken into account radically. This way, we highlight the problematics that involves the Freudian energetic concepts, specially the affect concept, and the risks that surround them and may lead to eventual undertaken projects of the psychoanalysis by the neurocientific theories. Therefore, instead of entering in the quantitative regime core presents since the beginning of the Freudian works and consequent nearings with neurocientific issues, we'll search to delimit the other approach possibility for the clinical and psychopathological events equally concernent to the psychoanalitic method: the exploration of language and meaning exploration.
\end{abstract}

KEYWORDS: Psychoanalisys; Language; Affect.

\section{Introdução}

Nos diferentes modelos formulados no interior do campo psicanalítico com o objetivo de especificar, classificar ou mesmo dar a conhecer os diferentes fenômenos psicopatológicos, em praticamente todos eles, o conceito de afeto acaba por desempenhar um papel central. Presente no cerne da metapsicologia freudiana e até mesmo antes dela, seja em textos freudianos, seja nos autores precedentes ao movimento psicanalítico, $\mathrm{o}$ afeto tem seu lugar de destaque. Interessante notar, contudo, que mesmo exercendo tamanha importância e despertando sobre si a atenção de diversos pesquisadores, seu estatuto conceitual permanece incerto. Dada a complexidade da questão, temos por certo que a saída para impasses envolvidos na definição do conceito de afeto não será alcançada por decreto, nem mesmo se esgotará nas poucas linhas de um artigo. Entretanto, se não nos cabe de antemão formular respostas, convém que nos dediquemos às perguntas, à especificação dos problemas gerais que circundam a concepção de afeto.

De quantidade a processos de descarga, de tonicidade intracerebral a pólo expressivo, de conceito operativo a fenômeno clínico, muitas transições e recortes podem ser atribuídos ao afeto na teoria psicanalítica, seja em Freud, seja nos demais teóricos. A descrição de sua história não pode ser vista como tarefa fácil ou desprovida de importância. De igual modo, devemos fazer a ressalva de que o critério cronológico pouco nos auxilia no que poderíamos chamar de reconstituição do conceito no interior do mosaico de micro-teorias de Freud a respeito. Uma vez que diferentes ramos da teoria e prática psicanalítica nascem de inserções diversas no continente do ensino freudiano, seria no mínimo ingênuo pensarmos em sua última aparição como a mais verídica e/ou bem acabada.

Logo, para encaminhar nossa incursão pelo tema, nos faremos valer da proposta de Bachelard de 
distinguir a reflexão historiográfica daquela propriamente epistemológica. Segundo o autor, enquanto o historiador toma idéias como fatos devendo primar pela sua disposição na linearidade da cadeia do tempo, ao epistemólogo cabe inversamente tomar fatos como idéias a serem inseridas em sistemas de pensamento (Bachelard, 1996, p. 22). Neste sentido, recortamos - como hipótese e guia - três maneiras recorrentes de conceituar o afeto em psicanálise, sobretudo na obra freudiana, buscando relacioná-las a diferentes precedentes e conseqüências epistemológicas. Dito de outra forma, defendemos que ao estudo das conceituações de afeto poderia ser somada a investigação sobre os critérios que comumente definem a existência do afeto, ou seja, a discussão acerca do nível epistemológico ao qual interessaria à teoria psicanalítica defender a realidade do objeto em questão.

Façamos por um breve momento o exercício de pensamento de deslocar nossa atenção da escolha quanto à veracidade e justeza dentre as argumentações para o exame de sua coerência lógica, sua possibilidade de formulação. Logo, caberia ao leitor antes de decidir o mérito ou não de cada leitura, buscar analisar se de fato já se defrontou com os tipos de argumentações que destacamos como possíveis à pergunta antes proposta, a saber, por quais critérios defendemos a existência do afeto no campo psicanalítico? Neste sentido, destacamos três linhas de leitura possíveis para o conceito de afeto que abordaremos na seqüência, a saber, as abordagens realista, metafórica e, por fim, nossa defesa de um estatuto semiótico do afeto.

\section{Abordagem realista do afeto}

Será em sua realidade mais dura que o afeto deverá ser explicado, através de uma hipotética existência substancial e objetiva? Talvez pudéssemos abranger sob tal jugo a caracterização do afeto primando por seu caráter quantitativo. Por entre aproximações e afastamentos com aportes biológicos, a obra freudiana certamente permite delimitações do afeto que portem como característica principal o aspecto de substancialidade. Vejamos um excerto do texto de Green para ilustrar tal posição:

$\mathrm{O}$ afeto de angústia permanece, portanto, ligado à impossibilidade de liquidação de uma tensão. A dimensão quantitativa permanece inelutável: o afeto é o resultado de uma quantidade de excitação não-ligável, não descarregável. (Green, 1982, p. 81).

Nesta vertente o afeto se coadunará com termos vizinhos, tais como os de catexia, investimento, energia e inervação, acentuando constantemente sua aspectualidade de objeto portador de características físicas, mesmo que provisoriamente indefinidas. Não raramente, Freud busca descrever tais características através de conjecturas de cunho biológico, como no seguinte exemplo:

Sou compelido - por outras razões - a retratar a liberação dos afetos como um processo centrífugo dirigido para o interior do corpo e análogo aos processos de inervação motora e secretória. Ora, assim como, no estado de sono, o envio de impulsos motores em direção ao mundo externo parece ficar suspenso, também é possível que a convocação centrífuga de afetos pelo pensamento inconsciente se torne mais difícil durante o sono. (Freud, 1900/1996b, p. 500).

Se, por um lado, seria igualmente plausível interpretar tais citações como possuindo cunho metafórico, como veremos adiante, por outro, não serão poucas as leituras que as abordam como defesa de uma teoria quantitativa dos afetos, de uma energética subjacente aos fenômenos psíquicos. É a partir de tal posição que se torna possível, por exemplo, o enquadre feito por Paes e Barros da submissão da economia freudiana aos preceitos termodinâmicos (Barros, 1998a e 1998b) ou ainda afirmações como a que expomos na íntegra:

Assim, o determinante químico é subjacente ao determinante psíquico. E Freud colocava seriamente todo o saber psicológico sob o rótulo de provisório, aguardando que o saber químico tome seu lugar, fornecendo-lhe seu substrato. Uma química integral seria, pois, o futuro da psicanálise. (Assoun, 1983, p. 65).

Tomado ao pé-da-letra, o argumento presente no conceito de afeto tido como elemento quantitativo de uma energética, seja de ordem biológica ou, em termos mais atuais, neuroquímica, permite a aproximação a modelos epistemológicos realistas e naturalistas. Realista na medida em que defende a existência do afeto não necessariamente como fenômeno, mas sim como entidade objetal independente da mente e da linguagem. ${ }^{1}$ Já a aproximação ao modelo naturalista ${ }^{2}$ se daria por conta de tentativas tão temerárias quanto recorrentes de subsumir o pensamento freudiano, para não dizer toda a psicanálise, ao projeto de redução dos fenômenos psíquicos a aportes físico-químicos. Tal intuito, para exemplificar apenas com um dos casos mais notórios ${ }^{3}$, pode ser encontrado na forma em que Pribam aborda a obra Projeto para uma Psicologia Cientifica (Freud, 1895/1996a), como bem mostra a passagem a seguir:

Argumentamos que a metapsicologia é uma neuropsicologia que pode ser modificada em termos da neurofisiologia atual; que os princípios reguladores são mais bem entendidos por referência aos progressos nas áreas da informação, controle e teoria de sistemas; que as formulações dos mecanismos memória-motivo, atenção, consciência e processos de pensamento são tão refinadas quanto quaisquer outras atualmente 
disponíveis e devem, portanto, passar a fazer parte da herança da psicologia cognitiva acadêmica. (Pribam \& Gill, 1976, p. 5).

Seria este o destino funesto a aguardar a teoria psicanalítica: tornar-se introdução histórica na academia de um saber mais bem acabado e abrangente? Certamente não é esta a posição mais condizente com o pensamento freudiano e sua aplicabilidade clínica. Entretanto, o redutivismo intrínseco à posição de autores como Pribam, Sulloway (Sulloway, 1998) e Jeannerod (Hochmann \& Jeannerod, 1991) seria logicamente aceitável, para não dizermos desejável, na justa medida em que nos mantivermos na defesa de um escopo realista e/ou naturalista de ciência e, por conseguinte, de argumentação. A questão a ser formulada seria então: uma vez estabelecidos conceitos sob os moldes epistemológicos realistas, o que nos impediria de levarmos a cabo as conseqüências epistemológicas de tal modelo de pesquisa? Ou ainda, a partir da definição de afeto enquanto quantidade substancial, não seria, portanto, mais lógico continuarmos freneticamente a busca pela definição das características físico-químicas que envolvem tal objeto? Esta parece ser a postura dos autores acima mencionados sem, contudo, respeitar o abismo epistemológico que separa seus planos de estudo daqueles diretamente vinculados ao pensamento freudiano. É nesse sentido que Stengers apontará a irracionalidade fundante do redutivismo em questão.

Vemos muitos físicos passar dum domínio do conhecimento que conhecem bem para extrapolações quanto ao real no seu conjunto. Por exemplo, quando neurofisiologistas passam dos neurônios à questão de saber o que é a subjetividade humana, ou à apreciação da psicanálise a partir do que sabem dos neurônios, a isso chamo eu irracionalidade. Em compensação, não podemos chamar-lhe irracionalismo, porque se crêem investidos do prestígio da ciência. (Stengers, 1987, pp. 66-67).

Não nos parece vantajosa, em função dos argumentos elencados, a situação de defesa do vetor epistemológico que se estende desde uma energética quantitativa e substancializada até uma postura eminentemente realista e/ou naturalista. Até mesmo porque, ao que procuramos salientar, no meio do vetor acabaríamos por encontrar a transposição total dos fenômenos clínicos (dentre eles o afeto) para determinantes de uma ordem totalmente outra.

\section{Abordagem metafórica do afeto}

Outra posição ainda plausível e a qual por diversas vezes somos instados a lançar mão é a da defesa de um estatuto metafórico para a energética freudiana. Sem fazer uso dos pressupostos realistas, e até mesmo como alternativa a eles, freqüentemente encontramos argumentos nos textos sobre teoria psicanalítica que propõem uma espécie de metaforização do afeto, primando não pela sua substancialidade quantitativa, mas sim pela sua operatividade conceitual.

Sem negar a possibilidade de abordagem de uma hipotética quantidade relativa ao afeto - mesmo que a lançando a um horizonte inalcançável - e, por vezes o definindo como um processo de descarga - sem igualmente caracterizar a entidade substancial da qual é o móvel -a posição quanto ao afeto aqui chamada de metafórica o torna um "algo" indefinido que, todavia, coloca em operação o conjunto teórico ao seu entorno. Vejamos um exemplo desta maneira de abordar o conceito:

Se o afeto é realmente, em certo sentido, "sofrido", ele serve também para designar aquilo que, vindo da "sensibilidade", põe em movimento alguma coisa da dinâmica psíquica. Essa noção "psicomotriz" vai passar, na metapsicologia freudiana, pela dupla idéia de "moção pulsional" (Triebregung) e de descarga característica do afeto - núcleo econômico-dinâmico que lhe assegura um estatuto na vida psíquica -, e não somente como emanando do "fundo afetivo". O "afeto" vem mesmo do corpo - ele exprime, nesse sentido, como veremos, algo do "fundo" corporal da "pulsão"; mas é a título de "móvel" que adquire uma significação psíquica de pleno direito. (Assoun, 1996, p. 153).

O enquadre epistemológico de tal postura necessitaria de uma discussão um tanto quanto mais aprofundada. Por ora, nos permitiremos apenas chamá-la de abordagem formalista e dar-lhe como característica principal a presença de uma sintaxe rigorosa em detrimento de sua semântica, já que se furta a maiores indicações dos objetos aos quais se dirige. Do mesmo modo, poderíamos encontrar a origem de tal linha de argumento em Freud na medida em que este, por repetidas vezes, acentua o caráter de irredutibilidade de sua energética aos meandros neurológicos sem, contudo, lançar mão de outro modo de ancoragem para tal ${ }^{4}$.

Para sermos breves, temos que, por corolário, a seguinte posição epistemológica quanto ao projeto freudiano não pode ser vista como livre de críticas. Dentre elas, consideramos as de Widlöcher (Widlöcher, 1986) como as mais ferrenhas. Segundo o autor:

Daí o recurso à noção de energia psíquica, que será seu único objeto definitivo de investigação clínica e a realidade última, mesmo que inobservável, do funcionamento mental. À caixa-preta que constitui, para o psicólogo, a atividade do cérebro, o psicanalista somará aquela do jogo pulsional. (Widlöcher, 1986, p. 38).

Restaria, segundo Widlöcher, a atitude ousada de propor modelos não-metafóricos, por mais incompletos que pudessem parecer, a serem colocados à prova na prática clínica. A alternativa mais viável, assim, passaria 
a ser a da não-oposição entre força e sentido, ou seja, retomar o aspecto econômico em termos de linguagem (Widlöcher, 1986, p. 61). É neste sentido que iremos expor a próxima abordagem.

Retomando os argumentos citados até o momento, podemos concluir em que situação pouco vantajosa encontra-se a teoria psicanalítica frente ao conceito de afeto, presa a uma encruzilhada na qual aparentemente apenas dois caminhos parecem se abrir: seguindo o primeiro, a teoria necessitará supor que as causas do sofrimento humano, assim como a multiplicidade dos fenômenos afetivos, teriam por base e origem os destinos de uma energia objetal ainda a ser especificada em suas características físicas. Se, ao contrário, trilhar o segundo caminho, terá que se confessar impossibilitada de formular um aparelho psíquico que seja convincente pela sua própria constituição - já que seu cerne declaradamente não poderia assumir as vezes de objeto.

Tampouco estes dois caminhos poderão ser percorridos sem conseqüências epistemológicas problemáticas. Ao se lançar no primeiro rumo, a psicanálise acabará se assumindo como práxis provisória, como teoria e clínica a ocupar temporariamente o lugar de uma ciência mais bem acabada que estaria por vir. Isto porque seu cerne estaria por ser desvendado em outro campo do qual não tem praticamente nenhuma participação. Interessaria à psicanálise adentrar de bom grado no projeto naturalista que antevê seu próprio fim e desqualifica sua prática e pesquisa? Certamente não.

Da mesma forma, sua situação ao posicionar-se na segunda trilha não teria conseqüências menos temerárias uma vez que põe seriamente em questão seu estatuto epistemológico. Isto porque assenta seu edifício teórico-prático num alicerce confessadamente vazio, na indefinição assumida do fundo conceitual que orienta seu campo de investigação. Sua defesa teria de dar-se, deste modo, pela crença absoluta em seus resultados práticos, colocando a pesquisa rigorosa em segundo plano. Entretanto, à encruzilhada acima descrita queremos supor a possibilidade de uma terceira via, largamente conhecida, porém, cada vez menos explorada: a da aposta firme no ancoramento da psicanálise no campo da linguagem. No próximo subitem nos dedicaremos à defesa de tal postura epistemológica bem como a uma breve tentativa de compreensão dos motivos de seu evitamento.

\section{Por um estatuto semiótico em psicanálise}

O estatuto da linguagem e, em decorrência dele, o lugar de um registro do sentido na história da psicanálise teve um itinerário, no nosso entender, não bem estimado em todas as suas arestas até hoje. Se não nos apegarmos a algum parti pris de antemão, devemos reconhecer que, em Freud, a psicanálise nasceu e se firmou sob a pressão colossal de duas forças de proveniência fortemente distintas: (a) uma epistemologia científica, herdada de seus estudos médicos, o conduziu à proposição de teoria criativa, bem informada e minuciosa, para a sua época, estabelecida em seus primeiros textos, sobretudo no Projeto para uma Psicologia Cientifica (Freud, 1895/1996a), amplamente subsumida num registro biológico, fisiológico ou neurológico, pouco importando o nome de cobertura; (b) uma epistemologia « hermenêutica », ou « semiótica », aplicando a esses termos um sentido mínimo, não conotado pelas ressonâncias que passaram a ter em inúmeras posições teóricas posteriores, isto é, subsumida no registro do « sentido », ou no registro « psicológico », tal como usado por ele mesmo.

A baliza que infletiu a psicanálise freudiana para este segundo registro - e que quase em consenso geral é admitido como o próprio marco de nascimento de sua psicanálise propriamente dita - está fincada na monumental investigação intitulada Interpretação dos sonhos (Freud, 1900/1996b). Logo na abertura do Capítulo 2 sobre o método da interpretação onírica, depois de analisar uma vasta literatura científica então disponível sobre os problemas oníricos (Cap. 1), diz Freud: "interpretar um sonho" significa indicar seu " sentido » (Freud, 1900/1996b, p. 406). O sonho passa a ser um objeto dignus intrari na investigação científica, justamente porque, ao invés de qualquer non sense e demais funções meramente fisiológicas, ele era, sobretudo, "pleno de sentido" para o movimento da alma. Desde então ficou postulado como a via real de acesso ao inconsciente, pelo mesmo Freud.

Toda a produção do criador da psicanálise, da adolescência médica à maturidade sexagenária, apresenta arestas pelas quais os adeptos de cada uma dessas duas forças de pressão encontram ecos e argumentos para atrair a psicanálise para as suas respectivas epistemologias. A definição marcada que o vienense deu para o conceito de pulsão, - em texto de cunho fortemente epistemológico, chamado por ele de metapsicológico, "A pulsão e seus destinos"5 (Freud, 1915/1996a); prezada desde então como epicentro das operações do inconsciente e situada num limiar quase indiscernível (e até hoje indecidível), justo no entremeio entre corpo e alma (psiquismo), tudo isso colocou a psicanálise numa posição delicada, de difícil resolução. Cabeça de Jânus, ela é cobrada a dar conta da face da pulsão voltada ao corpo, e seus reclames neuro-excitatórios, e ao mesmo tempo da face da pulsão voltada à alma, e seu trabalho de elaboração ou interpretância da pressão corporal. Esse trabalho do psiquismo em absorver os destinos da pulsão vai compor, nos textos posteriores de Freud, toda a dinâmica dos conflitos que se darão entre as instâncias rivais no inconsciente (id, ego, superego), 
ou seja, na sua tópica, regulada (ou desregulada) pela tensão quantitativa dos investimentos e afetações tidas como economia psíquica (Freud, 1996e). Eis um desenho mínimo e global, a nosso ver, de como o criador do inconsciente nos deixou nas mãos sua cria, no primeiro terço do século de sua existência.

A nos fiarmos na leitura de Lacan, nos anos cinqüenta do século de sua vida, pelos rumos que tomou nas Instituições mais tradicionais, no continente e no novo mundo americano, a psicanálise ficou descaracterizada e descentrada em relação ao núcleo forte do pensamento freudiano, núcleo este calcado no registro do sentido. Em textos dessa época - como "Variantes da cura-tipo" ou "Situação da psicanálise e formação do psicanalista em 1956" (Lacan, 1966) - Lacan lamenta a fragilidade teórica que permeava a estandardização da técnica analítica. Constata grande dispersão tanto na coordenação dos conceitos quanto na sua compreensão, em que se cai em sincretismos de pura ficção, propiciados pela fraqueza da invenção então notada. Pleiteia uma "formalização teórica", sem a qual nenhuma cura pode alcançar o estatuto de analítica, a despeito de poder estar "forrada de conhecimentos psicanalíticos" (Lacan, 1966, pp. 323-362).

Apoiado na convicção de que a psicanálise freudiana pede para ser vista como concatenada em conceitos, jamais em preceitos, Lacan acaba por lamentar a literatura "desencorajante" do meio psicanalítico, incapaz de introduzir qualquer noção nova, signo de "discordância difusa" que, ou deixa de lado os termos freudianos ou, quando os utiliza, é sempre "qualquer outra coisa que se designa". Tomam-se os conceitos freudianos por qualquer intuição imediata, através de analogia "grosseira" com os de « força » ou de « onda », sem que se tenha qualquer competência no domínio da física. Noções como « afeto, vivência, atitude, descarga, necessidade de amor, agressividade latente, armadura do caráter, ferrolho da defesa...» não passam, segundo Lacan, de "metáforas do compacto". Enfim, considera o discurso vigente como o de uma "extraordinária cacofonia". Esse o tônus de seu entendimento (Lacan, 1966, pp. 458-463).

O que nos importa aqui não é propriamente dar aval incondicional aos adjetivos lacanianos, mas sublinhar o contexto no qual, sob o mote do retorno a Freud, o psicanalista francês procurou mover o mundo da psicanálise com a alavanca da sua tese maior: a estrutura linguageira do inconsciente. As implicações decisórias da tese e suas conseqüências conceptuais eram tamanhas que vale a pena aqui ceder a palavra a seu discípulo, considerado dileto e direto, pelo peso que teve (e ainda tem) nos desdobramentos da psicanálise do seu mestre:

Ela [a tese] implica que os conceitos inventados por Freud, sem cessar corrigidos e multiplicados por ele, tomam sua necessidade e sua razão ao serem relacionados com a estrutura de linguagem [itálicos nossos], quer se trate do inconsciente ou da pulsão, da transferência ou da repetição, do fantasma, do narcisismo, da angústia, da sexualidade, mas também do conceito do psicanalista e da própria psicanálise. (Miller, 1978, p. 15).

Noutros termos, essa tese programática deveria governar toda a conceptualização do campo, desde o a quo, nascente onde tudo brota, lá no terreno obscuro onde a pulsão arranca do corpo seu fio de prazer e gozo - a própria coisa freudiana - até o ad quem, onde tudo deságua e se manifesta no mar dos sintomas idiossincráticos do sujeito, estando nos intervalos disso toda a fenomenologia que a clínica encontra no seu sofrimento e que a teoria tenta organizar na forma de seus conceitos (denegação, recalque, repetição, transferência, sublimação...).

Ora, quer-nos parecer que, sem precisar enumerar as razões todas, (a) seja por decréscimo de convicção do próprio mentor, (b) seja pelos mal-entendidos que cercaram todo o movimento estruturalista, (c) seja ainda por não ter seu promotor sabido estimar todo o valor e peso paradigmático (sentido kuhniano) da tese do "inconsciente estruturado como uma linguagem", (d) seja enfim por não termos sabido até hoje destilar dela um prolongamento mais conseqüente, o certo é que a tese ficou datada, circunscrita ao que se habituou chamar de um dos "registros" lacaniano (o registro do Simbólico, que sucedeu o do Imaginário e cedeu a vez ao do Real). Em nossas convicções, a despeito de tudo o que Lacan conseguiu com a tese, a pujança de desenvolvimentos que poderiam ser obtidos a mais é de tal ordem que nos faz entender ter sido apenas um vigoroso botão que secou antes mesmo de se abrir plenamente em flor.

Perdido o lastro paradigmático e relegada a tese a curto momento de 'namoro' de Lacan com a Lingüística e com o estruturalismo, sem algum casamento mais estável, a psicanálise pós-lacaniana corre o risco de estar deserdada epistemologicamente, em que pesem muitos esforços, gênios pessoais, em tentativas teóricas de maior brilho aqui e ali. É difícil saber se é legítimo suspeitá-la de estar correndo o risco de recair nas analogias 'grosseiras', nas 'metáforas do compacto' ou nos 'sincretismos de pura ficção' que o próprio Lacan encontrou no seu tempo. Mas presumimos ser legítimo perguntar se, sem o lastro mais firme de um paradigma - cujo estatuto um filósofo da envergadura de Karl-Otto Apel (Apel, 1987) reconhece como sendo a terceira prima philosophia (paradigma que rege o cerne do entendimento de uma época) da história do pensamento ocidental, qual seja o paradigma da linguagem ou paradigma semiótico - sem esse lastro, a psicanálise dificilmente evitará o risco de se ver engolida pelo paradigma concorrente, o das ciências fisiológicas, mormente as neurociências, movimento 
que encontra no conceito de afeto e seu corolário uma fácil porta de entrada.

Como paliativo para tentar evitar isso, o que vemos predominar no cenário psicanalítico pós-lacaniano são textos que demonizam a farmacologia, a psiquiatria ou as neurociências em geral, que ridicularizam o saber médico dessas ciências. Sem atacar diretamente as fragilidades de sua configuração epistemológica, os textos em questão se dão por satisfeitos ao desdenhar o avanço alheio, como se isso fosse suficiente, sob a espécie de síndrome fóbica perante o caminhar da ciência. Ora, é a nosso ver possível responder a elas num nível epistemológico mais lúcido e argumentado.

No nosso entendimento, a psicanálise encontra-se verdadeiramente entre duas escolhas forçadas: ou reata compromisso teórico-conceptual com o paradigma semiótico, registro do sentido, episteme da linguagem - não importam os títulos - e forja aí sua armadura epistemológica para entender todo o fenômeno psicanalítico (em decorrência da citação anterior de Miller) como estruturável segundo as coerções do discurso: a fala verbal nas lamentações, o discurso gestual nos humores, o discurso dos semblantes no olhar, enfim o discurso somático nos sintomas 'enervados' - Freud dizia jocosamente que, quando o inconsciente não consegue falar pela boca, ele o faz pelos poros do corpo (citado por Gay, 1989); ou então ela não saberá defender-se de sua paulatina diluição numa 'neuropsicanálise' (o termo já é pleiteado hoje, aqui e ali), como etapa intermediária a uma neurobiologia final ou fatal. A linguagem como condição do inconsciente é um sério desafio, ainda não enfrentado a contento.

\section{Notas}

* O co-autor agradece à CAPES pelo incentivo à pesquisa através da bolsa de doutorado.

1 Para evitar cairmos em contradições, faremos uso do Dicionário Oxford de Filosofia para a definição de tais termos. Segundo ele: "Um realista sobre um assunto A pode sustentar (I) que os tipos de coisas descritas por A existem; (II) que sua existência é independente de nós, ou que não são objetos produzidos pela nossa mente, linguagem ou esquema conceitual; (III) que as afirmações que fazemos em A não são redutíveis a outros tipos de afirmações que possam afinal revelar ser acerca de outra coisa que não A; (IV) que as afirmações que fazemos em A têm condições de verdade, constituindo descrições inequívocas de aspectos do mundo, sendo verdadeiras ou falsas em função dos fatos do mundo; (V) que conseguimos obter verdades acerca de A, e que é apropriado acreditar completamente no que afirmamos em A." (Blackburn, 1997, pp. 335).

2 Por naturalismo, o mesmo dicionário terá por definição "uma simpatia pela perspectiva segundo a qual em última análise nada resiste às explicações das ciências naturais. Um naturalista opõe-se, por exemplo, ao dualismo mente- corpo, uma vez que deixa o lado mental das coisas fora do alcance das explicações biológicas ou físicas (...)." (Blackburn, pp. 261).

3 Outros exemplos, por certo mais extravagantes, podem ser encontrados na esperanças de Weinberg (Weinberg, 1996, pp. 43-44) de encontrar explicações físicas e químicas redutíveis à mecânica quântica para os correlatos da consciência ou na de Everett de encontrar a "função de onda do Universo", onde estaria incluso, obviamente, o conjunto dos observadores (in: D’Eespagnat, 1994, pp 263-264).

4 Apenas para exemplificar, citaremos o seguinte trecho: "Mas todas as tentativas para, a partir disso, descobrir uma localização dos processos mentais, todos os esforços para conceber idéias armazenadas em células nervosas e excitações que percorrem as fibras nervosas, têm fracassado redondamente. (...) Verifica-se aqui um hiato que, por enquanto, não pode ser preenchido, e não constitui tarefa da psicologia preenchê-lo." (Freud, 1915/1996d, p. 179, itálicos nossos).

5 Texto traduzido para o português como "Os Instintos e suas vicissitudes". No atual artigo é utilizado um título mais aproximado sentido original.

\section{Referências Bibliográficas}

Apel, K. O. (1987). La sémiotique transcendantale et les paradigmes de la Prima Philosophia. Révue de métaphysique et de morale, 92(2), pp. 147-163.

Assoun, P.-L. (1983). Introdução à Epistemologia Freudiana. Rio de Janeiro: Imago.

Assoun, P.-L. (1996). Metapsicologia Freudiana: uma introdução. Rio de Janeiro: Jorge Zahar Ed.

Bachelard, G. (1996). A Formação do Espirito Científico: Contribuição para uma psicanálise do conhecimento. Rio de Janeiro: Contraponto.

Barros, C. P. (1998a). Conceitos termodinâmicos e evolucionistas na estrutura formal da metapsicologia de Freud. Cadernos do Tempo Psicanalítico, 3, Rio de Janeiro: Sociedade de Psicanálise Iracy Doyle, pp. 13-51.

Barros, C. P. (1998b). Contribuição à controvérsia sobre o "ponto de vista econômico". Cadernos do Tempo Psicanalítico, 3, Rio de Janeiro: Sociedade de Psicanálise Iracy Doyle, pp. 53-89.

Blackburn, S. (1997). Dicionário Oxford de Filosofia. Rio de Janeiro: Jorge Zahar.

D’Espagnat, B. (1994). Le Reél Voilé: Analyse des concepts quantiques. Paris: Libraire Arthème Fayard.

Freud, S. (1996a). Projeto para uma Psicologia Científica In Edição standard brasileira das Obras Completas de Sigmund Freud (Vol. I, pp. 335-454). Rio de Janeiro: Imago (Original publicado em 1950).

Freud, S. (1996b). A Interpretação dos sonhos. In Edição standard brasileira das Obras Completas de Sigmund Freud, Vols. 4 e 5. Rio de Janeiro: Imago. (Original publicado em 1900).

Freud, S. (1996c). Os Instintos e suas Vicissitudes. In Edição standard brasileira das Obras Completas de Sigmund Freud (Vol. XIV, pp. 115-144). Rio de Janeiro: Imago. (Original publicado em 1915).

Freud, S. (1996d). O Inconsciente. In Edição standard brasileira das Obras Completas de Sigmund Freud (Vol. XIV, pp. 163-222). Rio de Janeiro: Imago. (Original publicado em 1915).

Freud, S. (1996e). Novas Conferências Introdutórias sobre Psicanálise, Conferência XXXI: a dissecção da personalidade 
psíquica. In Edição standard brasileira das Obras Completas de Sigmund Freud (Vol. XXII, pp. 63-84). Rio de Janeiro: Imago. (Original publicado em 1933).

Gay, P. (1989). Freud - uma vida para nosso tempo. São Paulo: Companhia das Letras.

Green, A. (1982). O Discurso Vivo: uma teoria psicanalítica do afeto. Rio de Janeiro: Editora Francisco Alves.

Hochmann, J. \& Jeannerod, M. (1991). Esprit, Où Est-Tu ? Paris: Editions Odile Jacob.

Lacan, J. (1966). Ecrits. Paris: Seuil.

Miller, J.-A. (1978). Algorithmes de la psychanalyse. Ornicar?, 16, pp. 15-23.

Pribam, K. \& Gill, M. (1976). O 'Projeto'de Freud: um exame crítico. São Paulo: Cultrix.

Stengers, I. (1987). Multiplicidade, razão e sentido In H. Reeves, R. Thom \& I. Stengers (Orgs.), Abordagens do Real (pp. 57-81). Lisboa: Publicações Dom Quixote.

Sulloway, F. (1998). Freud, Biologiste de l'Esprit. Paris: PUF.

Weinberg, S. (1996). Sonhos de uma Teoria Final. Rio de Janeiro: Rocco.

Widlöcher, D. (1986). Métapsychologie du Sens. Paris: PUF.

Waldir Beividas é Doutor em Lingüística e Semiótica pela USP (1992), e pós-doutoramento na EHESS (1999)

- Paris, foi professor do Programa de Pós-Graduação em Teoria Psicanalítica, na UFRJ (de 1993 a 2006).

Atualmente é professor no Departamento de Lingüística e Semiótica da USP. Endereço: Universidade de São Paulo - FFLCH - Departamento de Lingüística. Av. Prof. Luciano Gualberto, 403 - Cx Postal: 2530 - CEP 01060-970. São Paulo, SP. E-mail: waldirbeividas@gmail.com

Tiago Ravanello é Formado em Psicologia pela Universidade Federal de Santa Maria, Mestre e Doutor em Teoria Psicanalítica pelo Programa de Pós-Graduação em Teoria Psicanalítica da Universidade Federal do Rio de Janeiro. Professor adjunto do curso de Psicologia da Universidade Federal de Mato Grosso do Sul (UFMS). Endereço para correspondência: Cidade Universitária, s/n. Sala 8, CCHS / UFMS. CP 549. CEP: 79070-900 -

Campo Grande / MS

\section{Linguagem como alternativa ao aspecto quantitativo em psicanálise \\ Waldir Beividas e Tiago Ravanello}

Recebido em: 06/12/2007

Aceito em: 02/06/2008 